\title{
Egg white gel structure determines biochemical digestion with consequences on softening and mechanical disintegration during in vitro gastric digestion
}

\author{
Geeshani Somaratne ${ }^{\mathrm{a}, \mathrm{b}}$, Aiqian $\mathrm{Ye}^{\mathrm{c}}$, Francoise Nau ${ }^{\mathrm{d}}$, Maria J. Ferrua ${ }^{\mathrm{c}, \mathrm{e}}$, Didier Dupont ${ }^{\mathrm{d}}$, \\ R. Paul Singh ${ }^{c, f}$, Jaspreet Singh ${ }^{\text {a,* }}$ \\ ${ }^{a}$ Riddet Institute and Massey Institute of Food Science and Technology, Massey University, Palmerston North, New Zealand \\ ${ }^{\mathrm{b}}$ Department of Food Science and Technology, Faculty of Agriculture, University of Peradeniya, 20450, Sri Lanka \\ ${ }^{\mathrm{c}}$ Riddet Institute, Massey University, Palmerston North, New Zealand \\ ${ }^{\mathrm{d}}$ STLO, INRAE, Institut Agro, 35042 Rennes, France \\ ${ }^{\text {e }}$ Fonterra Research and Development Centre, Palmerston North, New Zealand \\ ${ }^{\mathrm{f}}$ Department of Biological and Agricultural Engineering, University of California, Davis, CA, USA
}

\section{A R T I C L E I N F O}

\section{Keywords:}

Diffusion

Disintegration

Softening

Mixed Weibull function

Human gastric simulator

\begin{abstract}
A B S T R A C T
The aim of this work was to investigate the role of biochemical digestion on softening and disintegration kinetics of $\mathrm{pH} 5$ and pH 9 egg white gel (EWGs) during in vitro gastric digestion. EWG samples (5 mm length cubes) underwent in vitro digestion by incubation in simulated gastric fluid at different time intervals for up to $240 \mathrm{~min}$. The hardness was measured using a Texture Analyser; softening kinetics was fit to the Weibull model. Results revealed that $\mathrm{pH} 9 \mathrm{EWG}$ had the highest softening halftime (458 $\pm 86 \mathrm{~min}$ ), indicating the slowest softening, whereas pH 5 EWG had the lowest softening halftime (197 $\pm 12 \mathrm{~min}$ ), indicating the quickest softening. The digested samples were immediately exposed to mechanical forces generated by the human gastric simulator (HGS) for 10 min to investigate the influence of gastric juice on the breakdown behaviour of EWG cubes. The breakdown behaviour of the disintegrated samples was characterized by fitting the cumulative distributions of particle surface areas to a mixed Weibull function $\left(R^{2}>0.99\right)$. The weight of fine particles $(\alpha)$ showed that regardless of gastric juice diffusion, the pH 5 EWG $(\alpha=0.22 \pm 0.03)$ disintegrated into more fine particles than those resulting from $\mathrm{pH} 9$ EWG disintegration $(\alpha=0.07 \pm 0.02)$. As expected, the diffusion of gastric juice enhanced erosion of the EWG particles into fine particles. Result obtained from the particle surface area distribution is in good agreement with the softening kinetics of EWGs during simulated in vitro gastric phase.
\end{abstract}

\section{Introduction}

As the primary stage in the digestion of food by the human body, mastication breaks down nearly all solid or semi-solid foods into smaller particles in the oral cavity (Bornhorst \& Singh, 2012; Chen, 2009, 2015). One of the foremost roles of mastication is the formation of a cohesive food bolus for safe swallowing and as a result of mastication, flavour and aroma release from disintegrated food structure (Bornhorst \& Singh, 2012). The bolus of food resulting from chewing is disintegrated into small particles under both repeated shearing and grinding of gastric contents by the antral contraction waves together with the biochemical degradation of acids and enzymes in the human stomach (Kong \& Singh, 2008a, 2009a, 2009b; Somaratne et al., 2020). For all forms of food, gastric digestion is greatly influenced by the initial characteristics of the food material properties, especially food composition and food structure (Ferrua, Kong, \& Singh, 2011; Kong \& Singh, 2008b; Singh, Ye, \& Ferrua, 2015). Thus, by altering the material properties of the ingested food, the structural variations will positively modify the nutrient release process through altering the gastric juice diffusion, biochemical disintegration as well as mechanical disintegration when exposed to the peristaltic activity of the stomach (Bornhorst \& Paul Singh, 2014; Singh et al., 2015; Somaratne et al., 2020). This might be taken into consideration for optimal design of novel foods towards the targeted and controlled delivery of nutrients.

For solid and semi-solid foods, the disintegration kinetics in the stomach is an important factor controlling the gastric emptying and

\footnotetext{
* Corresponding author.

E-mail address: J.X.Singh@massey.ac.nz (J. Singh).
} 
subsequent nutrient release kinetics (Guo, Ye, Lad, Dalgleish, \& Singh, 2014; Guo et al., 2015; Kong \& Singh, 2008b, 2009a). Due to the importance of monitoring food particle breakdown in the gastric environment, techniques including image analysis, sieving and laser diffraction were proposed to quantify changes in particle size distribution of foods during in vitro and in vivo gastric digestion (Bornhorst, Kostlan, \& Singh, 2013; Drechsler \& Ferrua, 2016; Guo et al., 2015; Nau et al., 2019). Additionally, mathematical models have been proposed to characterise the in vitro and in vivo disintegration kinetics of solid food during gastric digestion (Bornhorst \& Paul Singh, 2014; Drechsler \& Ferrua, 2016). Previously researchers have also attempted to describe the disintegration of food during digestion with the use of texture analysis methods and they also proposed that softening halftime is a good indicator to monitor food breakdown during gastric digestion (Bornhorst, Ferrua, \& Singh, 2015; Drechsler \& Bornhorst, 2018). Despite extensive research directed at the gastric digestion process, the establishment of the proper relationship between the initial material properties of foods and their subsequent breakdown during gastric digestion is still far from being fully understood. Furthermore, there have been relatively few studies aimed at understanding the influence that biochemical processes have in the degradation of food and its mechanical breakdown within the stomach.

Protein is one of the most important macronutrients in food and the digestion of protein is initiated by the acid and pepsin in the stomach (Luo, Boom, \& Janssen, 2015). Eggs are widely consumed around the world as an important source of protein in the human diet (Miranda et al., 2015). Due to their functional properties, egg white proteins are extensively used in the formation of food gels with different structures that have considerable potential to serve as a functional food with controlled delivery properties (Nyemb, Causeur, et al., 2016). The behaviour of different egg white gel (EWG) structures in simulated gastric environments has recently received considerable attention. In particular, Nyemb, Causeur, et al. (2016), Nyemb, Guérin-Dubiard, et al. (2016), reported that the overall proteolysis of egg white protein is higher when granular spongy EWG (pH 5 EWG) are submitted to in vitro gastric digestion, as compared to smooth rigid EWG (pH 9 EWG). Similarly, micro- and macro-structural changes in EWG matrices have been presumed responsible for different in vivo rates of protein digestion and gastric emptying (Nau et al., 2019). Using FRAP analysis and hyperspectral imaging technique, previous studies have shown that the EWG microstructure strongly influences the extent of gastric pepsin and acid diffusion into pH 5 and pH 9 EWGs (Somaratne, Nau, et al., 2019a; Somaratne, Reis, et al., 2019). However, despite these observations, there remains a poor understanding of the influence of the diffusion of gastric juice into EWGs on their mechanical disintegration and softening kinetics during in vitro gastric digestion.

With the aim of making up the insufficiency of the current studies, this research proposes to identify the role of gastric juice diffusion and simultaneous biochemical digestion on the rate of softening and mechanical disintegration of $\mathrm{pH} 5$ and $\mathrm{pH} 9$ EWG structures during in vitro gastric digestion. In the present study, EWGs with two different microstructures but equal protein concentration (10\%) were produced by varying the $\mathrm{pH}$ conditions ( $\mathrm{pH} 5$ and $\mathrm{pH}$ 9). The Human Gastric Simulator (HGS) was employed to investigate the disintegration kinetics of $\mathrm{pH} 5$ and $\mathrm{pH} 9$ EWGs under simulated gastric conditions. Texture analysis was used to determine the softening kinetics, with a focus on the effect of the gastric juice diffusion into different EWGs on their breakdown behaviour in the gastric environment. By unravelling, the underlying physicochemical processes that occur during gastric digestion, this study could develop a better understanding of the role that biochemical digestion has on softening kinetics and breakdown mechanics in the EWG models.

\section{Materials and methods}

\subsection{Materials}

Fresh eggs were purchased from a local supermarket in Palmerston North, New Zealand. Eggs were stored at room temperature $\left(25^{\circ} \mathrm{C}\right)$ and used within no more than five days. To reduce the influence of possible variations among the initial samples, the same batch of eggs was used for the entire study. The protein concentration of egg white $(10.5 \pm 0.28 \%)$ was determined by the Kjeldahl method $(\mathrm{N} \times 6.25)$.

Pepsin (from porcine gastric mucosa, $\geq 250 \mathrm{U} / \mathrm{mg}$ solid), a gastric lipase analogue (from Aspergillus niger $\geq 120,000 \mathrm{U} / \mathrm{mg}$ solid) and $\alpha$-amylase (from Aspergillus oryzae $\geq 30 \mathrm{U} / \mathrm{mg}$ ) were used. All chemicals and enzymes were obtained from Sigma Aldrich (St. Louis, MO, USA). The simulated salivary fluid (SSF) and simulated gastric fluid (SGF) were prepared using the electrolyte stock solutions according to the harmonised INFOGEST protocol, described in Minekus et al. (2014).

\subsection{Preparation of $E W G s$}

EWGs were prepared as described previously in Nyemb, GuérinDubiard, et al. (2016). Briefly, fresh egg white solution was homogenized using an IKA T-18 Ultra Turrax Digital Homogenizer (10,000 rpm) for $1 \mathrm{~min}$. The required quantities of $2 \mathrm{M} \mathrm{HCl}$ or $2 \mathrm{M} \mathrm{NaOH}$ were added to the egg white solution to achieve $\mathrm{pH} 5$ or $\mathrm{pH} 9$, respectively. Finally, Type-1 ultrapure water (MilliQ, Millipore Corp.) was used to achieve a protein concentration of $10 \%$ in both $\mathrm{pH} 5$ and $\mathrm{pH} 9$ egg white solutions. These solutions were then put in sealed plastic cylindrical containers (inner diameter $20 \mathrm{~mm}$ ) and were heated in a water bath for $60 \mathrm{~min}$ at $80{ }^{\circ} \mathrm{C}$. After heating, the gels were cooled and kept at $4{ }^{\circ} \mathrm{C}$ for $20 \mathrm{~min}$. Then gels were removed from the plastic casings and cut into $5 \mathrm{~mm}$ length cubes using a metal wire mesh cutter.

\subsection{Static in vitro digestion}

EWG samples were digested according to the harmonized INFOGEST protocol (Brodkorb et al., 2019; Minekus et al., 2014). Briefly, each EWG sample (100 g) was first submitted to a 2 min in vitro oral phase by mixing the EWG sample with simulated saliva containing $75 \mathrm{U} / \mathrm{mL}$ amylase ( $1 \mathrm{~mL} \mathrm{SSF} / \mathrm{g}$ food sample) using a $37^{\circ} \mathrm{C}$ shaking water bath (BS11, Lab Companion) at $50 \mathrm{rpm}$. Subsequently, the $\mathrm{pH}$ was adjusted to 3.0 with $1 \mathrm{M} \mathrm{HCl}$. Then the sample was mixed with SGF containing pepsin $(2000 \mathrm{U} / \mathrm{mL})$ and lipase $(120 \mathrm{U} / \mathrm{mL})$ and the sample was then placed inside the shaking water bath $\left(37^{\circ} \mathrm{C}, 50 \mathrm{rpm}\right)$.

Individual samples were used for each replicate of each digestion time. Thus, 24 samples from one treatment (either $\mathrm{pH} 5$ or $\mathrm{pH} 9$ EWG) were prepared according to the above procedure and placed into the shaking water bath at $37{ }^{\circ} \mathrm{C}$ at $50 \mathrm{rpm}$ and incubated at different time intervals up to $4 \mathrm{~h}$ ( $0 \mathrm{~min}$ - control sample, $10 \mathrm{~min}, 20 \mathrm{~min}, 40 \mathrm{~min}, 60$ $\mathrm{min}, 120 \mathrm{~min}, 180 \mathrm{~min}$, and $240 \mathrm{~min}$ ). The order in which the samples were digested in vitro was randomised. Immediately after each digestion time, EWG samples were neutralized using $0.5 \mathrm{M} \mathrm{NaHCO}_{3}$. Then $\mathrm{pH} 5$ and $\mathrm{pH} 9 \mathrm{EWGs}$ cubes were separated from the gastric juice using a sieve and then following textural and breakdown measurements of EWG cubes were measured, immediately.

\subsection{Hardness determination using texture profile analysis}

The texture profile analysis of digested pH 5 and pH 9 EWG cubes was performed using a Texture Analyser TA-XTPlus (Texture Technologies, Stable Microsystems, Surrey, UK). One EWG cube was placed on the base plate of the TA-XTPlus with a cylindrical flat-end aluminium probe ( $35 \mathrm{~mm}$ in diameter) using a $5 \mathrm{~kg}$ load cell. The crosshead speed was $0.5 \mathrm{~mm} / \mathrm{s}$, with a rest period of $5 \mathrm{~s}$ between cycles and the deformation was $50 \%$ of the original length. The maximum force $(\mathrm{N})$ recorded during the compression measurement (peak force of the first 
compression cycle in N) is referred to as the hardness of sample. Three separate replicates were performed for each EWG type and digestion time point and eight determinations were performed per each replicate for each gastric digestion time.

\subsection{Weibull model parameters and softening halftime determination}

The hardness change kinetics were fit to the Weibull model, according to Bornhorst et al. (2015), using the following equation:

$\frac{\mathrm{H}_{\mathrm{t}}}{\mathrm{H}_{\mathrm{o}}}=\mathrm{e}^{-\mathrm{kt}(\beta)}$

where $H_{t}$ is the hardness $(N)$ at time $t ; H_{0}$ is the initial hardness $(N)$; $k$ is the scale parameter, which may indicate the rate of change in hardness $\left(\mathrm{min}^{-1}\right)$; $\mathrm{t}$ is the digestion time (min); and $\beta$ is the distribution shape factor (dimensionless). The goodness of fit between the experimental and predicted values was determined using the error sum of squares (SSE) and the coefficient of determination $\left(\mathrm{R}^{2}\right)$.

The softening halftime $\left(\mathrm{t}_{1 / 2}\right)$ was calculated as the time required for the initial hardness to be reduced by $50 \%$ using the following equation:

$\mathrm{t}_{1 / 2}=\frac{1}{\mathrm{k}}(\ln (2))^{\frac{1}{\beta}}$

where $\mathrm{k}$ is the scale parameter and $\beta$ is the distribution shape factor of Weibull model.

\subsection{Mechanical disintegration of EWGs using a human gastric simulator}

The influence of gastric juice diffusion and subsequent biochemical digestion of the $\mathrm{pH} 5$ and $\mathrm{pH} 9$ EWG cubes on their breakdown behaviour was analysed by exposing the soaked samples to a dynamic HGS for $10 \mathrm{~min}$. The HGS provides a realistic and predictive simulation of mechanical and grinding forces within the human stomach (Ferrua \& Singh, 2015; Kong \& Singh, 2010). However, the HGS used in this study was not intended to reproduce the actual physicochemical reactions that develop during digestion, but to provide an initial framework to characterize the influence of gastric juice on the break down mechanics of the $\mathrm{pH} 5$ or $\mathrm{pH} 9$ EWG samples.

The latex stomach chamber was lined with a thin polyester mesh bag (pore size of the mesh bag is approximately $1 \mathrm{~mm}$ ), which permits only particle size of less than $1 \mathrm{~mm}$ to pass as a gastric digesta. A plastic tube was connected to the bottom of the stomach chamber in order to remove the gastric digesta (particles of size $<1 \mathrm{~mm}$ ) from the system during the digestion process. The peristaltic contractions on 4 sides of the latex stomach chamber were generated by six pairs of equally spaced rollers attached with the four conveyor belts. The mechanical contraction frequency was 3 times/min, mimicking the peristalsis in a human stomach. The temperature inside the human gastric chamber was maintained at $37{ }^{\circ} \mathrm{C}$.

The method of operating the HGS was adapted from the procedures described by Guo et al. (2015). pH 5 and pH 9 EWG samples (100 g) were subjected to simulated static in vitro digestion (oral and gastric phase) as described in Section 2.3. Then, the digested sample with neutralized gastric juice was loaded into the stomach chamber. For control sample (0 min digestion), pH 5 and pH 9 EWG samples (100 g) were directly loaded into the HGS, and instead of neutralized gastric juice, an equal amount of water was added into the stomach chamber. The samples were exposed to the mechanical forces applied by the HGS for $10 \mathrm{~min}$ and then, gastric digesta were removed from the bottom of the stomach, manually.

\subsection{Determination of particle size distribution using image analysis}

The breakdown mechanics of the pH 5 and pH 9 EWGs were assessed on combined digesta, which include the cumulative emptied digesta and the digesta retained in the simulated latex stomach chamber. It was characterized based on image analysis of their particle size distributions according to the method described by Drechsler and Ferrua (2016). Three representative aliquots of the sub-samples $(5 \mathrm{~mL})$ were randomly taken for each combined digesta and it was dispersed in $20-30 \mathrm{~mL}$ of water in a rectangular petri dish $(12.2 \mathrm{~cm} \times 8.0 \mathrm{~cm})$. In order to prevent touching of particles with each other during imaging, the number of petri dishes required increased up-to 3 to 10 , as soaking time progressed. Particles were dyed with a $0.5 \%$ Bromophenol blue solution to increase their contrast against the background. Each petri dish was manually shaken for good dispersion and placed on a LED lightbox and the image was taken using a digital camera (Nikon 1 V1, AF-S DX Micro NIKKOR $40 \mathrm{~mm} \mathrm{f} / 2.8 \mathrm{G}$ macrolens).

The number and surface area of all the particles present in each individual petri dish were then analysed using a custom-built code in Matlab 2013a (MathWorks, Natick, Mass., USA) software and the results were expressed as a cumulative percentage of the surface area of the particles. The custom-built codes were used to convert the images from each petri dish to a grayscale image. Then the contrast between particles and background was enhanced by readjusting the intensity as described in Drechsler and Ferrua (2016). After that the image was converted to black and white, with black regions representing particles. The size distribution of the particles (in terms of their relative numbers and associated surface areas) was computed and averaged over all subsamples. To facilitate the comparison among different treatments, the size distribution of the particles was analysed over one hundred size classes ranging from $10^{-4} \mathrm{~mm}^{2}$ to $100 \mathrm{~mm}^{2}$.

As illustrated in Fig. 1, Drechsler and Ferrua (2016), developed a framework to characterise the damage mechanisms undergone by the potato samples during the simulated gastric phase. In particular, based on the size distribution of compressed particles compared to their initial size $\left(A 0 \sim 25 \mathrm{~mm}^{2}\right.$ ), it is possible to quantify the amount of product associated with undamaged particles (A0 $>15 \mathrm{~mm}^{2}$ ), fragments $(1.75$ $\left.\mathrm{mm} 2<\mathrm{A} 0<15 \mathrm{~mm}^{2}\right)$, chips $\left(1 \mathrm{~mm} 2<\mathrm{A} 0<1.75 \mathrm{~mm}^{2}\right)$ and fine debris $\left(\mathrm{A} 0<1 \mathrm{~mm}^{2}\right.$ ) during the gastric digestion process (Drechsler \& Ferrua, 2016). Based on this classification framework, we have evaluated the contribution of surface erosion and particle fragmentation on the breakdown of EWG particles due to the exposure of gastric juice and the mechanical forces generated by the HGS.

\subsection{Modelling of particle breakdown during gastric digestion}

The earlier study by Drechsler and Ferrua (2016), reported that the mixed Weibull distribution function can successfully be used to describe the extent and the mechanism of particle breakdown of potatoes during in vitro gastric digestion. That work highlighted that the double-form of breakage distribution function (i.e. mixed Weibull distribution function) may be more appropriate to describe the particle surface area distribution of a comminuted food than the single-form breakage distribution function such as a Rosin Rammler distribution function.

Thus, the cumulative percentage of particle surface area $\left(F_{(x)}\right)$ for each sample and digestion time was fit to a mixed Weibull distribution function, involving two shape parameters (k), two scale parameters $(\lambda)$, and one weight parameter $(\alpha)$, using the following equation:

$\mathrm{F}_{(\mathrm{x})}=\alpha\left(1-\mathrm{e}^{-\left(\frac{\mathrm{x}}{\lambda 1}\right)^{\mathrm{k} 1}}\right)+(1-\alpha)\left(1-\mathrm{e}^{-\left(\frac{\mathrm{x}}{12}\right)^{\mathrm{k} 2}}\right)$

where $F_{(x)}$ is the cumulative particle size distribution of the sample ( 0 to $1) ; \mathrm{x}\left(\mathrm{x}=\mathrm{A} / \mathrm{A}_{0}\right)$ is the particle surface area $\left(\mathrm{A} \mathrm{mm}^{2}\right)$ in relationship to its initial value $\left(\mathrm{A}_{0} \mathrm{~mm}^{2}\right) ; \alpha$ is a mixing weight parameter that represents the proportion of the first mode (left Weibull distribution); $\lambda 1$ and $\lambda 2$ are the scale parameters established by left (first mode) and right (second mode) Weibull distribution, respectively; and $\mathrm{k} 1$ and $\mathrm{k} 2$ are the shape parameters established by left (first mode) and right (second mode) 


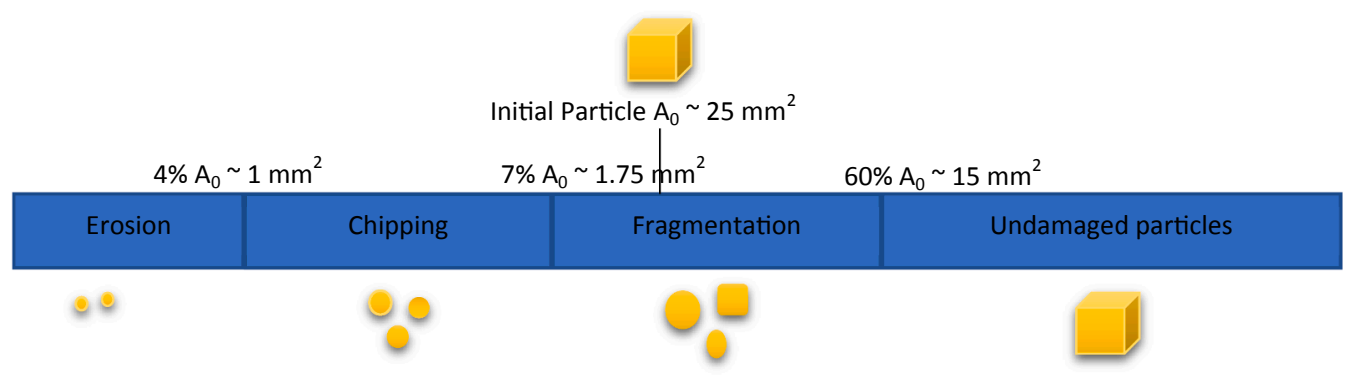

Fig. 1. Characterisation of broken particles into fine debris, fragments and undamaged product based on their relative size to the original one before comminution, according to Drechsler and Ferrua (2016).

Weibull distribution, respectively. The model parameters were determined using nonlinear regression techniques in Matlab (MathWorks, Natick, Mass., USA). The more details of the method for estimating parameters of mixed Weibull distribution and the custom-built code program used in Matlab has been outlined by Drechsler and Ferrua (2016).

\subsection{Statistical analysis}

An ANOVA was conducted using a 2-factor factorial design to determine differences in hardness and mixing weight parameter $(\alpha)$ during static in vitro gastric digestion. The factors were the type of EWG (pH 5 and pH 9 EWGs) and digestion time (0-240 min). Tukey test was used to analyse the differences between means and statistical significance was assessed at a level of $\mathrm{p}<0.05$. The Student $t$-test was used to assess differences in the Weibull model parameters and softening halftime. Minitab 17 software was used for statistical analysis.

\section{Results and discussion}

\subsection{Choice of experimental parameters}

The size of the EWG cubes was selected to be $5 \mathrm{~mm}$ in length, which is similar to the upper limit of the actual size range of most of the solid/ semi-solid foods after oral mastication (Jalabert-Malbos, MishellanyDutour, Woda, \& Peyron, 2007). The upper limit after oral mastication was chosen because the EWG samples should not completely break down during the $4 \mathrm{~h}$ of the gastric digestion period in order to achieve the objectives of this study that are to quantify textural changes and particle size breakdown processes during digestion. In addition, a simple geometry (cube) was essential for limited variation in textural measurements. These criteria were considered for selection of $5 \mathrm{~mm}$ in length $\mathrm{pH} 5$ or pH 9 EWG cubes for the study. In this study, four hours of digestion time was selected because most solid foods are cleared from the human stomach approximately within 3-4 h (Minekus et al., 2014). As mentioned in the Section 2.6, the HGS test used in this study was not projected to mimic the real physicochemical reactions that develop during gastric digestion, but to provide an initial framework to characterize the influence of gastric juice on the break down mechanics of the $\mathrm{pH} 5$ or $\mathrm{pH} 9$ EWG samples. Thus, preliminary studies were conducted, and then identified that pre-soaked $\mathrm{pH} 5$ or $\mathrm{pH} 9$ EWG cube samples that were exposed to the mechanical forces generated by the HGS for 10 min provide a representative particle size distribution, and thereby facilitate to identify the mechanisms underlying the breakdown behaviour. Moreover, pre-soaked pH 5 or pH 9 EWG cube samples exposed to the mechanical forces generated by the HGS for more than 10 min results in fine debris of all the end-products whereas less than 10 min results in many undamaged particles.

\subsection{Softening kinetics of EWGs during gastric phase is influenced by the initial EWG characteristics}

The hardness (peak force at the first compression cycle, in $\mathrm{N}$ ) of the pH 5 and pH 9 EWGs over the 240 min gastric digestion is shown in Table 1. Changes in the hardness of the EWG cubes were significantly ( $\mathrm{p}$ $<0.05$ ) influenced by the type of EWG and digestion time. For both $\mathrm{pH} 5$ and $\mathrm{pH} 9 \mathrm{EWGs}$, the hardness significantly decreased with increasing digestion time. The softening thus occurring during digestion in EWGs could be due to the proteolysis of egg white protein due to gastric pepsin. In addition, the water uptake from the EWG matrix during gastric digestion process (Somaratne, Reis, et al., 2019) may also be associated with the hardness reduction of EWGs during gastric digestion.

pH 9 EWG had a significantly higher initial hardness compared to the pH 5 EWG $(4.83 \pm 0.13 \mathrm{~N}$ compared to $2.39 \pm 0.07 \mathrm{~N})$, likely due to the more compact and microstructurally homogeneous gel formed by egg white proteins at pH 9 (Somaratne, Nau, et al., 2019a, 2019b). In contrast, the microstructure of the pH 5 EWG was characterised by a spatially heterogeneous loose protein matrix made of larger aggregate particles (Somaratne, Nau, et al., 2019a, 2019b), which lead to a lower initial hardness. Throughout the gastric digestion, pH 9 EWG maintained a higher hardness compared to pH 5 EWG.

Results further indicate that initial EWG texture and microstructure impact reduction in hardness during gastric digestion. The looser microstructure of pH 5 EWG caused the gel to disintegrate more quickly, and to a greater extent, leading to a higher rate of hardness reduction. In contrast, the compact-dense microstructure of the pH 9 EWG showed a slower reduction of hardness, likely due to reduced accessibility of pepsin along with gastric juice to its EWG matrix. In particular, after 240 min of digestion, pH 5 EWG exhibited the greatest change $(66 \%$ decrease) from its initial hardness value, whereas only $40 \%$ decrease was observed in the case of $\mathrm{pH} 9$ EWG.

The Weibull distribution function has been widely used to describe the softening kinetics of solid foods during static in vitro gastric digestion (Bornhorst et al., 2015; Drechsler \& Bornhorst, 2018). In the present study also, the experimental data of softening during gastric digestion (Fig. 2) fit well to the Weibull model (Eq. (1)), as evidenced by the high

Table 1

Changes in the hardness $(\mathrm{N})$ of the $\mathrm{pH} 5$ and $\mathrm{pH} 9$ EWGs during in vitro gastric digestion.

\begin{tabular}{lll}
\hline Digestion time (min) & Hardness of pH 5 EWG $(\mathrm{N})^{*}$ & ${\text { Hardness of pH 9 EWG }(\mathrm{N})^{*}}^{\text {P }}$ \\
\hline 0 & $2.39 \pm 0.07^{\mathrm{f}}$ & $4.83 \pm 0.13^{\mathrm{a}}$ \\
10 & $2.10 \pm 0.02^{\mathrm{fg}}$ & $4.41 \pm 0.30^{\mathrm{ab}}$ \\
20 & $1.96 \pm 0.07^{\mathrm{fgh}}$ & $4.31 \pm 0.16^{\mathrm{b}}$ \\
40 & $1.83 \pm 0.03^{\mathrm{gh}}$ & $4.17 \pm 0.17^{\mathrm{b}}$ \\
60 & $1.63 \pm 0.18^{\mathrm{hi}}$ & $4.01 \pm 0.14^{\mathrm{bc}}$ \\
120 & $1.38 \pm 0.12^{\mathrm{ij}}$ & $3.62 \pm 0.18^{\mathrm{cd}}$ \\
180 & $1.07 \pm 0.05^{\mathrm{jk}}$ & $3.43 \pm 0.18^{\mathrm{d}}$ \\
240 & $0.81 \pm 0.08^{\mathrm{k}}$ & $2.88 \pm 0.16^{\mathrm{e}}$ \\
\hline
\end{tabular}

*Values are means \pm standard deviations $(n=24$ cubes). Different letters within each column and raw represent statistically different means $(\mathrm{p}<0.05)$. 


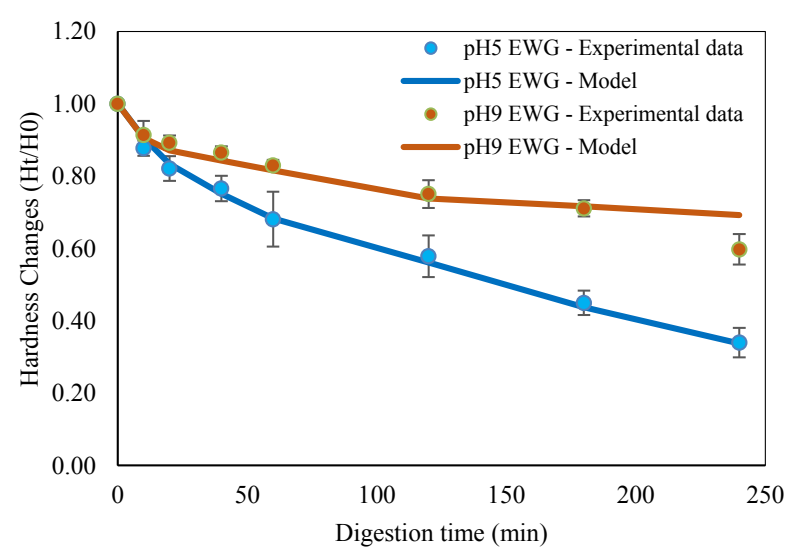

Fig. 2. Softening curves of the $\mathrm{pH} 5$ and $\mathrm{pH} 9$ EWGs during in vitro gastric digestion based on the hardness $(\mathrm{N})$ measurements. Values are means $(n=3)$ with error bars as standard deviations. The solid lines represent the predicted values from the average Weibull model parameters shown in Table 2.

coefficient of determination values $\left(\mathrm{R}^{2}=0.95-0.98\right.$, Table 2) and low error sum of squares (SSE $<0.01$, Table 2). The reported softening rate constants of the Weibull function (k) demonstrated that the pH 5 EWG showed a higher rate of softening $\left(\mathrm{k}=0.004 \mathrm{~min}^{-1}\right)$ compared to $\mathrm{pH} 9$ EWG $\left(\mathrm{k}=0.002 \mathrm{~min}^{-1}\right)$. The $\beta$ values for both $\mathrm{pH} 5$ and $\mathrm{pH} 9 \mathrm{EWGs}$ are less than 1, indicating a higher rate of softening at the initial stage of the gastric digestion process followed by an exponential decrease in the hardness of EWG with digestion time.

The halftime $\left(t_{1 / 2}\right)$, i.e. the time to reach $50 \%$ reduction of initial hardness, incorporates both the $\mathrm{k}$ and $\beta$ parameters from the Weibull model, and thus more appropriately describes the overall curve properties than either one of the fitted parameters on its own (Bornhorst et al., 2015). Results show that pH 9 EWG, which had the highest initial hardness ( $4.83 \pm 0.13 \mathrm{~N}$ ), also had the longest softening halftime (458 $\mathrm{min}$ ), indicating a slower softening than pH 5 EWG which had the lowest initial hardness $(2.39 \pm 0.07 \mathrm{~N})$ and the shortest softening halftime (197 $\mathrm{min}$ ). These differences observed between both EWGs probably reflect the differences in their initial texture and microstructure that may result in different rates of pepsin, moisture and/or acid diffusion. Indeed, it was previously established that the loosened microstructure of the $\mathrm{pH} 5$ EWG leads to faster pepsinolysis, moisture and acid diffusion during in vitro gastric digestion compared to the denser structure of $\mathrm{pH} 9$ EWG (Somaratne, Nau, et al., 2019a; Somaratne, Reis, et al., 2019). The relevance of these findings on the breakdown response of the EWG samples are discussed in the following sections.

\subsection{Mechanisms of particle breakdown depend on the initial structure of the EWGs}

During the gastric phase, gastric juice diffused into the EWG structure, thus simultaneously favouring the softening of gel particles and pepsinolysis of egg white protein inside the gel cubes/particles (Nyemb,

\section{Table 2}

Parameter values of Weibull function (Eq. (1)) fitted to the softening curves of the $\mathrm{pH} 5$ and $\mathrm{pH} 9$ EWGs during in vitro gastric digestion. Values represent the average model parameters or softening half time from 3 digestion trials \pm standard deviation. Means within each column followed by different superscript letters are significantly different $(\mathrm{p}<0.05)$.

\begin{tabular}{llllll}
\hline & $\mathrm{K}$ & $\mathrm{B}$ & $\mathrm{R}^{2}$ & $\mathrm{SSE}$ & $\mathrm{t}_{1 / 2}(\mathrm{~min})$ \\
\hline pH 5 EWG & $0.004 \pm 0.00^{\mathrm{a}}$ & $0.90 \pm 0.02^{\mathrm{a}}$ & 0.98 & 0.01 & $197 \pm 12^{\mathrm{b}}$ \\
pH 9 EWG & $0.002 \pm 0.00^{\mathrm{b}}$ & $0.92 \pm 0.03^{\mathrm{a}}$ & 0.95 & 0.00 & $458 \pm 86^{\mathrm{a}}$ \\
\hline
\end{tabular}

$\mathrm{k}$ is the rate of change in hardness $\left(\mathrm{min}^{-1}\right) ; \beta$ is the distribution shape factor (dimensionless); $\mathrm{R}^{2}$ is the coefficient of determination or goodness of fit; SSE is the error sum of squares; $\mathrm{t}_{1 / 2}$ is the softening halftime (min).
Causeur, et al., 2016), and both phenomena might have some impact on the mechanical disintegration of the EWGs due to the stomach movements. Therefore, the influence of gastric juice diffusion and subsequent biochemical digestion on the breakdown mechanics of the $\mathrm{pH} 5$ and $\mathrm{pH}$ 9 EWGs was investigated by exposing the soaked EWG samples (digested or not) to the mechanical forces generated by the HGS.

From a nutritional point of view, the amount of nutrients that are entrapped within the digested particles - or, on the contrary, those released from the food particles - is an important indicator (Drechsler \& Ferrua, 2016). Thus, analysing the breakdown behaviour of food during gastric digestion in terms of the particle size is a better indicator of the amount of nutrients associated with food matrix than distributions of the number of particles (Drechsler \& Ferrua, 2016). The distributions of particle size (surface area) in the disintegrated pH 5 and pH 9 EWG samples are depicted in Figs. 3 and 4.

Fragmentation, chipping and erosion are the major mechanisms responsible for solid food disintegration in a simulated gastric environment (Drechsler \& Ferrua, 2016; Kong \& Singh, 2009a). Based on the classification framework proposed by Drechsler and Ferrua (2016), (Fig. 1), an attempt was made to evaluate the contribution of surface erosion, chipping and particle fragmentation on the breakdown of EWG particles due to the exposure of gastric juice and the mechanical forces generated by the HGS.

According to the Figs. 3 and 4, without exposure to gastric juice (0 min, control sample), the pH 5 and pH 9 EWGs exhibited both undamaged particles and the fine debris particles. Even without any exposure to gastric juice, $\mathrm{pH} 5$ EWG showed more fine debris than $\mathrm{pH} 9$ gels, and it could be due to the loose and pours microstructure of pH 5 EWG which facilitate rapid breakdown as a result of the mechanical forces generated by the HGS. These distributions revealed the significant amount of nutrients still present inside large particles $\left(\mathrm{A}_{0}>15 \mathrm{~mm}^{2}\right)$ in the disintegrated control samples. However, even if there are mainly large particles, some small hydro soluble nutrients (i.e. peptides) could be released into the gastric medium.

On the contrary, as the digestion proceeds, the particle size progressively decreased for both EWGs as demonstrated by the increasing percentages of the small particles such as chips $\left(1 \mathrm{~mm}^{2}<\mathrm{A}_{0}<1.75\right.$ $\mathrm{mm}^{2}$ ) and fine debris $\left(\mathrm{A}_{0}<1 \mathrm{~mm}^{2}\right)$. Interestingly, this progressive size reduction due to previous exposure to gastric juice followed different types of breakdown mechanisms for the pH 5 and pH 9 EWG samples.

The breakdown of the pH 5 EWG appears to be driven by fragmentation, chipping as well as surface erosion mechanisms when the gel is exposed to gastric juice up to $20 \mathrm{~min}$, since mainly fragmented, chips and fine debris particles are observed within the samples (Fig. 3). It can be assumed that the diffusion of gastric juice into the pH 5 EWG causes a fast reduction of the internal cohesive forces that hold the pH 5 EWG matrix together, consistently with the fast softening previously reported (Table 2). Consequently, when the stress applied by the HGS was greater than the internal cohesive forces inside the pH 5 EWG matrix, it may lead to extensive fragmentation of particles as soon as the digestion began. When the exposure to gastric juice progressed, the percentage of fragmented particles decreased markedly, and the percentage of chipped particles increased steadily; this is especially visible within the $\mathrm{pH} 5$ EWG samples exposed to $120 \mathrm{~min}$ of gastric digestion. As further exposure to gastric juice increases, the distribution of chips shifted towards smaller sizes, likely due to the increased softening of the $\mathrm{pH} 5$ EWG. Finally, the pH 5 EWG exposed to simulated gastric fluid for more than 120 min exhibited considerable breakdown as the number of fine debris particles $\left(<1 \mathrm{~mm}^{2}\right)$ increased and the distribution curve shifted towards the left (Fig. 3). Somewhat similar breakdown behaviour has been previously reported by Guo et al. (2015), for a soft whey protein emulsion gel. This soft gel had a faster disintegration than hard gels in the HGS, which resulted from both abrasion and to some extent fragmentation.

The pH 9 EWG showed that the weight percentage of large particles $\left(>15 \mathrm{~mm}^{2}\right.$ ) decreased progressively over gastric digestion (Fig. 4). The 

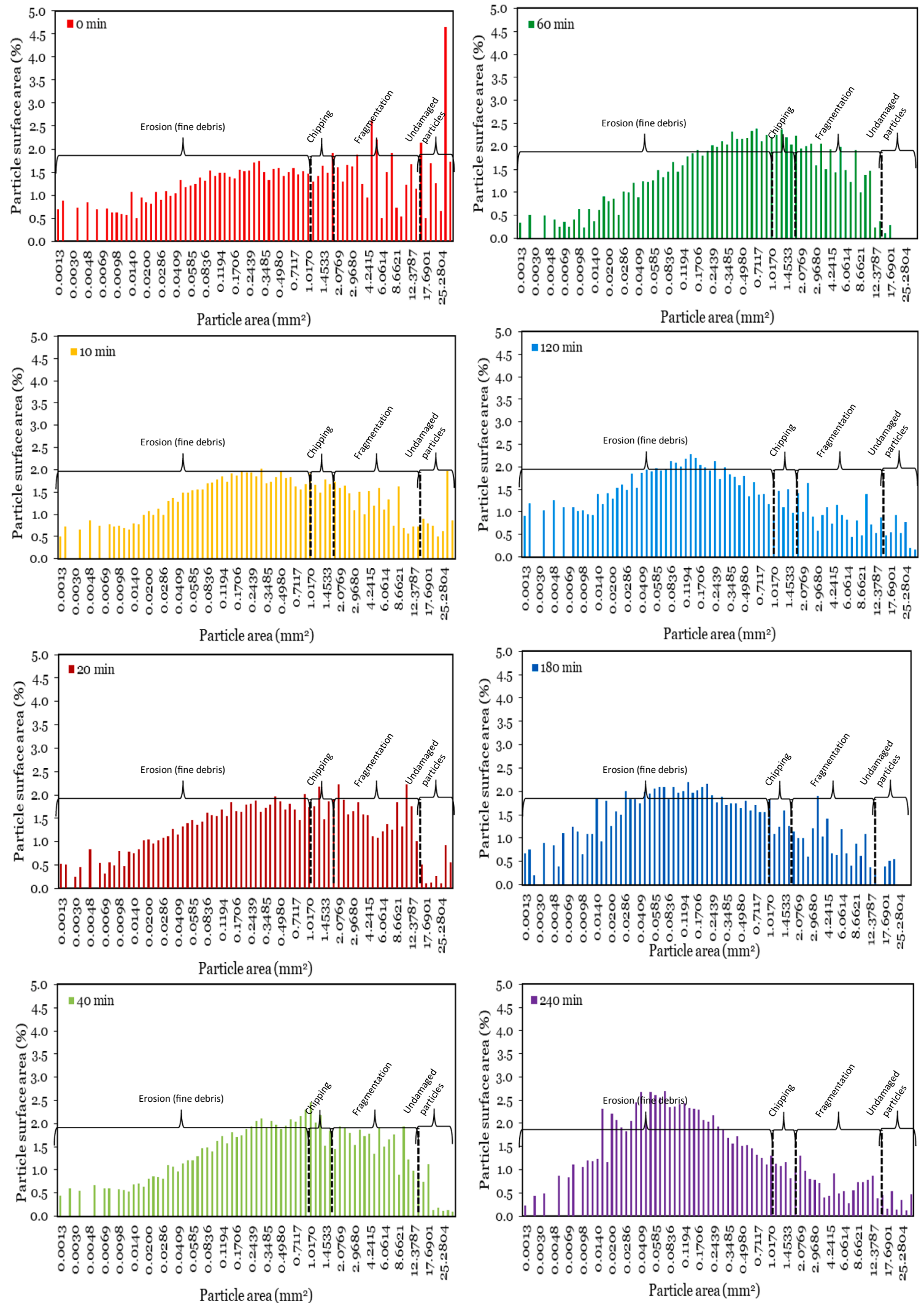

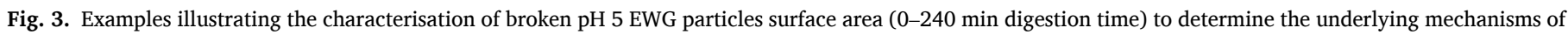
EWG breakdown during the gastric phase. 


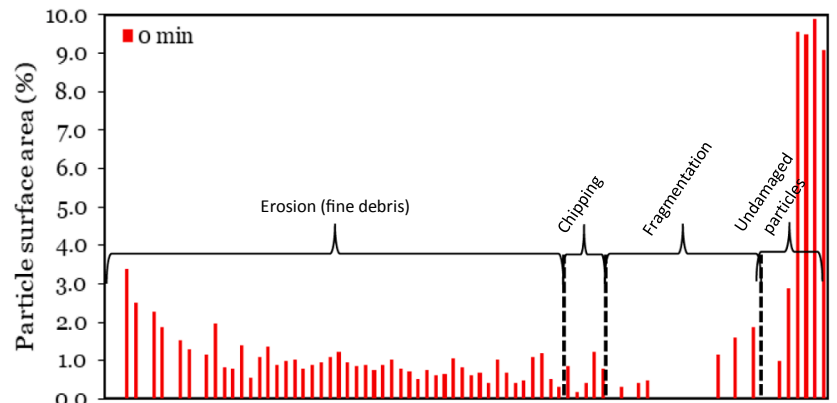

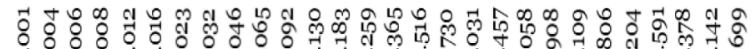

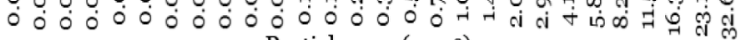
Particle area $\left(\mathrm{mm}^{2}\right)$

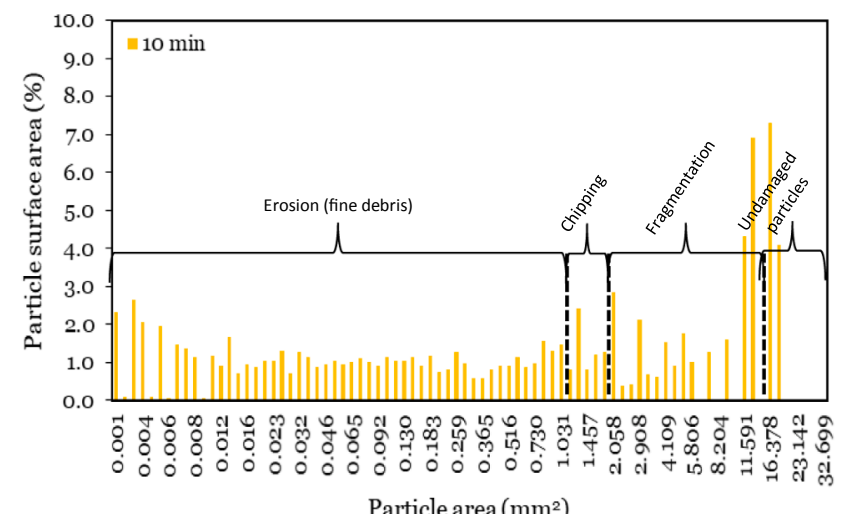

Particle area $\left(\mathrm{mm}^{2}\right)$
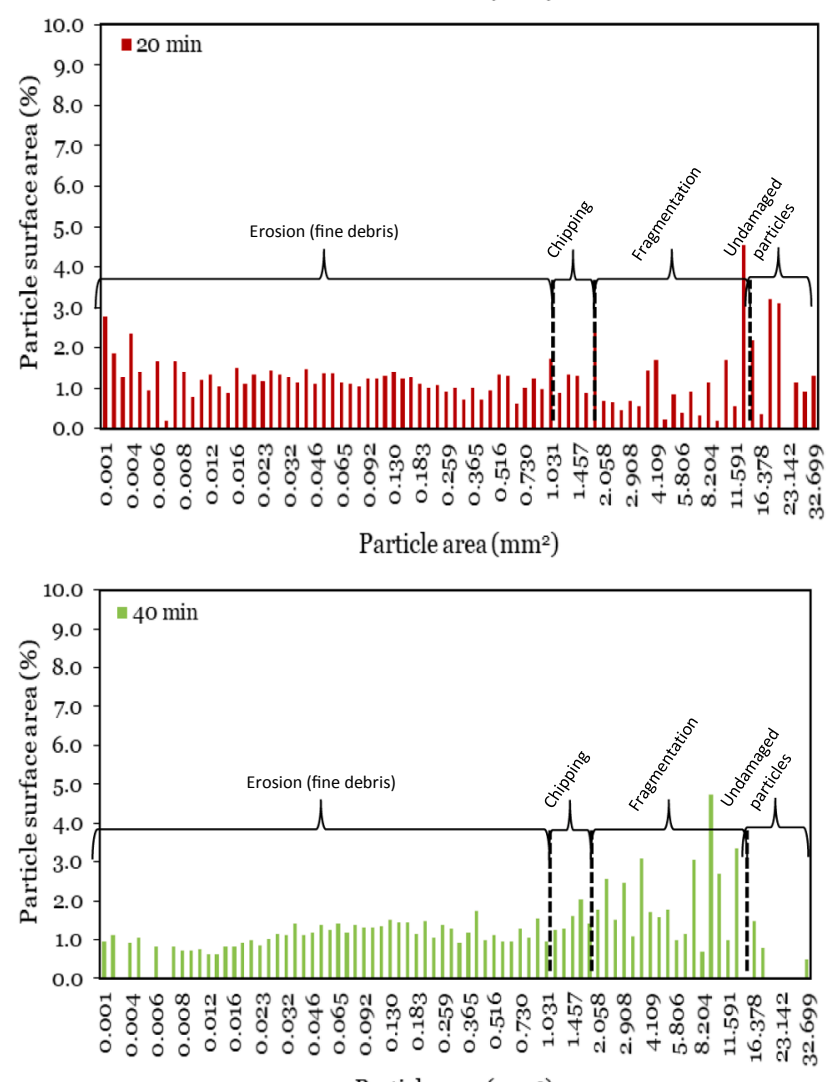

Particle area $\left(\mathrm{mm}^{2}\right)$
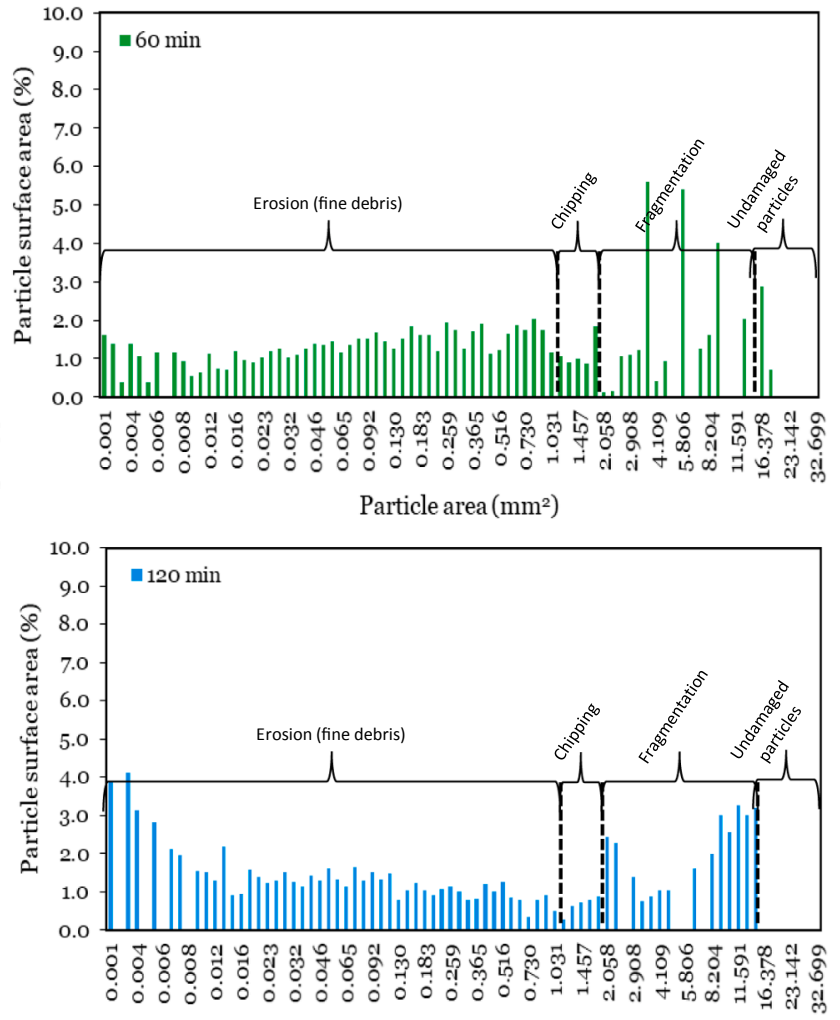

Particle area $\left(\mathrm{mm}^{2}\right)$

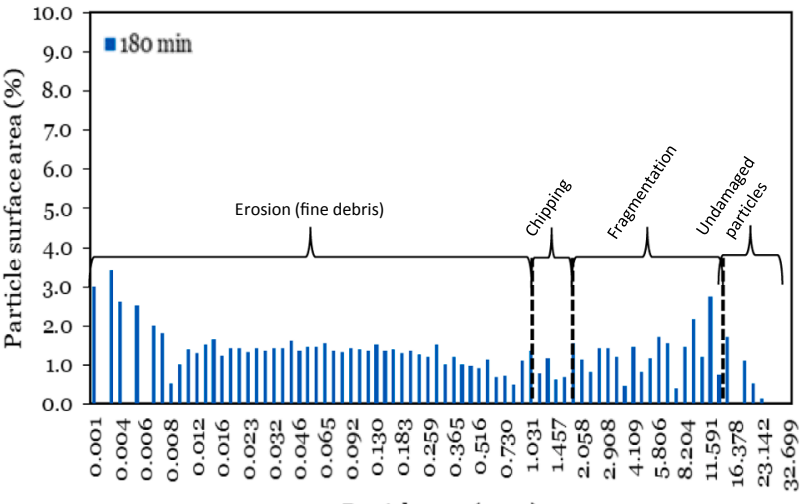

Particle area $\left(\mathrm{mm}^{2}\right)$

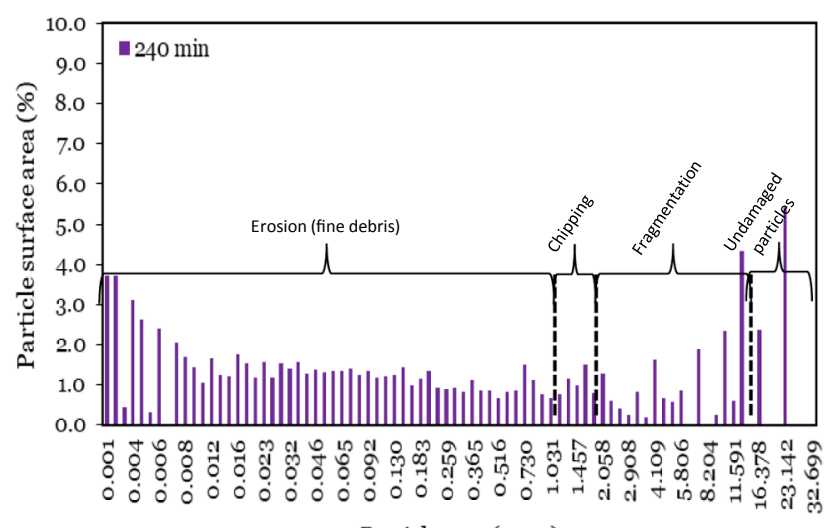

Particle area $\left(\mathrm{mm}^{2}\right)$

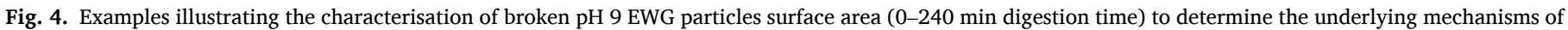
EWG breakdown during the gastric phase. 
main mechanisms that can explain the particle size distributions of $\mathrm{pH} 9$ EWG exposed to gastric digestion over $240 \mathrm{~min}$ are the erosion of the matrix into fine debris, with a progressive reduction in the size of initially undamaged particles due to fracture or chipping mechanisms. Unlike pH 5 EWG, smaller particles $\left(<0.008 \mathrm{~mm}^{2}\right)$ of $\mathrm{pH} 9$ EWGs were increasing the most rapidly. On the contrary, the size classes between $0.012 \mathrm{~mm}^{2}$ and $1.5 \mathrm{~mm}^{2}$ do not appear to change sizably. Thus, surface erosion may be one of the predominant mechanisms of pH 9 EWG disintegration during in vitro gastric phase. A similar trend was observed by Guo et al. (2015), when they examined the simulated gastric digestion of whey protein emulsion gels using the HGS; those gel samples that had a hard texture had a much slower disintegration largely governed by abrasion compared to soft gels. Therefore, the disintegration mechanism, in the HGS, of the EWGs previously exposed to the gastric juice can be explained based on their initial hardness and microstructure. The maximum magnitude of the destructive force from the human stomach is around 1.9 N (Kamba, Seta, Kusai, Ikeda, \& Nishimura, 2000). Then, the low initial hardness of pH 5 EWG (around 2.4 N) suggests this gel can be broken down quickly into smaller fragments in the HGS, whereas the much higher initial hardness of pH 9 EWG (around $4.8 \mathrm{~N}$ ) might explain the relevance of the erosion mechanism in the disintegration of this gel and the particular low impact of fragmentation mechanism. On the other hand, EWGs became softer and then likely easier to break apart after diffusion of gastric juice. Then, as reported in Somaratne, Nau, et al. (2019a, 2019b), pepsin diffusivity was higher inside the flexible, highly anisotropic, porous and the granular network of the pH 5 EWG than inside the rigid, highly isotropic, less porous and smooth network of the pH 9 EWG. Therefore, the result was greater changes of the microstructure of $\mathrm{pH} 5 \mathrm{EWG}$, and a larger effect on the weakening and disintegration of this gel. Another factor possibly contributing to the greater resistance of the $\mathrm{pH} 9$ EWG to breakdown under the stomach conditions could be the higher initial $\mathrm{pH}$ of the gel (Somaratne, Nau, et al., 2019b). Indeed, this could locally induce high $\mathrm{pH}$ despite the addition of gastric fluid, thus limiting the proteolytic action of pepsin on the $\mathrm{pH} 9$ gel proteins in agreement with the observations of Nau et al. (2019). These authors further underlined that smooth-rigid EWG (similar to pH 9 EWG) is more elastic, cohesive and viscoelastic than the granular-spongy EWGs (similar to pH 5 EWG). Thus, the smooth-rigid EWG is more resistant to breakdown and likely to break up forming harder particles.

\subsection{Role of biochemical and mechanical effects on the breakdown process of $\mathrm{pH} 5$ and $\mathrm{pH} 9 \mathrm{EWG}$}

The cumulative particle surface area distributions of $\mathrm{pH} 5$ and $\mathrm{pH} 9$ EWGs after 10 min exposure in HGS and for 0 to 240 min prior gastric digestion are shown in Fig. 5. At the beginning of gastric digestion, curves exhibited a bimodal distribution behaviour, with one component associated with fine debris $\left(<1 \mathrm{~mm}^{2}\right)$ and another with particles similar in size to the original cubes $\left(\sim 25 \mathrm{~mm}^{2}\right)$. However, exposures to gastric juice not only enhance the weight of fine particles within the samples but also shift their distribution in different manners. In one hand, as soaking time increase, and more EWG cubes collapse, the distribution of particles shifted towards larger sizes (up to $100 \mathrm{~mm}^{2}$ ) until most of the cubes are damaged. On the other hand, as expected, upon longer exposure to gastric juice, the distribution of particles shifted towards smaller sizes (i.e. curves shifted towards the left) due to the increased softening of the EWG matrix (Fig. 5). The results are in agreement with Drechsler and Ferrua (2016).

All the cumulative distributions of particle surface areas well fitted to mixed Weibull models, as indicated by correlation coefficients $\left(\mathrm{R}^{2}\right)$ all higher than 0.99 (Table 3). The particle surface area distribution exhibited a bimodal distribution behaviour, with one component associated with fine debris (first mode of the mixed Weibull distribution) and another with particles similar in size to the original cubes or somewhat larger than that of original cubes due to the collapse of the matrix

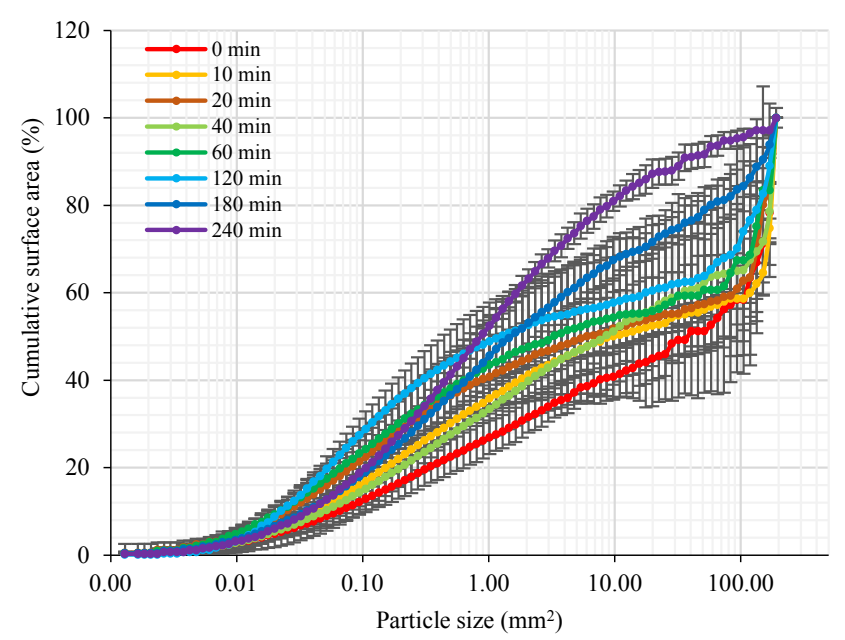

(a)

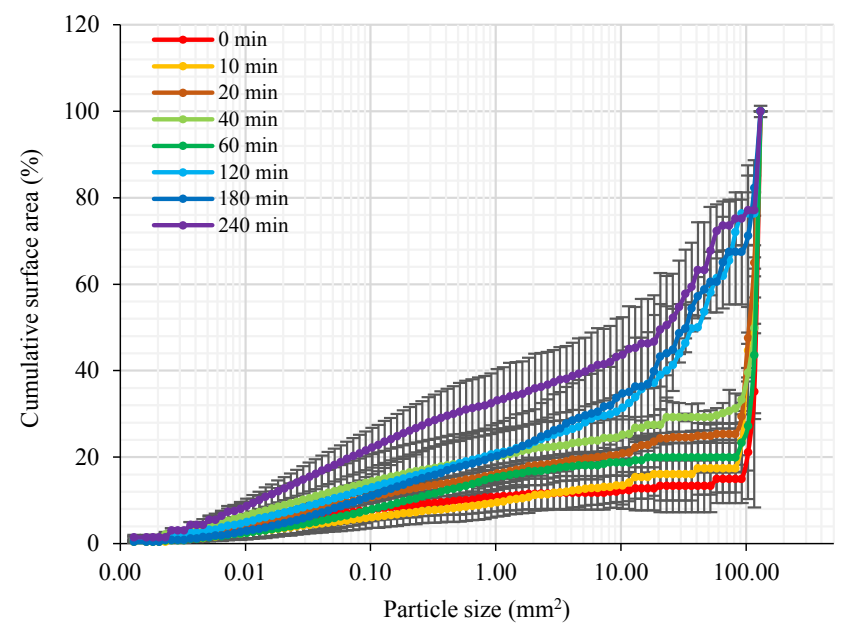

(b)

Fig. 5. Cumulative particle surface area distributions for (a) $\mathrm{pH} 5$ and (b) $\mathrm{pH} 9$ EWGs after 10 min HGS, EWG samples when pre-soaked in gastric juice for different periods of time $(0-240 \mathrm{~min})$. Values are given as averages $(\mathrm{n}=3)$ with error bars as standard deviation.

(second mode of the mixed Weibull distribution). The scale parameter $(\lambda)$ is a constant representing the broadness (i.e. when $\lambda$ increases, the height of the Weibull distribution decreases and the broadness increases) whereas the shape parameter $(\mathrm{k})$ is a constant representing the shape (i.e. sigmoidal shape when $\mathrm{k}>1$, or parabolic shape when $\mathrm{k}<1$ ) of the Weibull distribution (Krifa, 2009). It is interesting to note that, the scale parameter of the first mode of the mixed Weibull distribution $(\lambda 1)$ value increased over the 240 min digestion period in both $\mathrm{pH} 5$ and $\mathrm{pH} 9$ EWGs, which indicate a broader distribution spread of the fine particles with increased digestion time (Table 3 ). In agreement with expectations, the scale parameter of the second mode of the mixed Weibull distribution $(\lambda 2)$ value decreased over the 240 min digestion period in both $\mathrm{pH} 5$ and $\mathrm{pH} 9$ EWGs, which indicate a narrower distribution spread of the large particles with increased digestion time (Table 3 ).

The extent of damage to the EWGs due to exposure to gastric juice and mechanical forces generated by the HGS was assessed based on the mixed Weibull parameter $(\alpha)$ that describes the weight effect of fine particles within the breakdown sample on the distribution. The temporal evolution of $\alpha$ parameter for $\mathrm{pH} 5$ and $\mathrm{pH} 9$ EWGs is shown in Fig. 6 . The weight parameter of fine particles $(\alpha)$ was significantly influenced by the EWG type, digestion time, and their interaction ( $p<0.05$, Fig. 6). As expected, the weight effect of fine particles significantly increased ( $p<$ 0.05 ) during the 240 min gastric digestion period for both $\mathrm{pH} 5$ and $\mathrm{pH} 9$ 
Table 3

Mixed Weibull Distribution Parameters. Values are given as averages $(n=3)$ with standard deviation.

\begin{tabular}{|c|c|c|c|c|c|c|c|c|c|c|}
\hline \multirow[t]{2}{*}{ Digestion time (min) } & \multicolumn{2}{|l|}{$\lambda 1$} & \multicolumn{2}{|l|}{ k1 } & \multicolumn{2}{|l|}{$\lambda 2$} & \multicolumn{2}{|l|}{ k2 } & \multicolumn{2}{|l|}{$\mathrm{R}^{2}$} \\
\hline & pH 5 EWG & pH 9 EWG & pH 5 EWG & pH 9 EWG & pH 5 EWG & pH 9 EWG & pH 5 EWG & pH 9 EWG & pH 5 EWG & pH 9 EWG \\
\hline 0 & $0.01 \pm 0.01$ & $0.01 \pm 0.00$ & $0.70 \pm 0.06$ & $0.79 \pm 0.07$ & $3.01 \pm 1.54$ & $27.3 \pm 2.5$ & $0.58 \pm 0.00$ & $0.50 \pm 0.04$ & $>0.998$ & $>0.993$ \\
\hline 10 & $0.21 \pm 0.00$ & $0.01 \pm 0.13$ & $0.79 \pm 0.01$ & $0.70 \pm 0.19$ & $1.34 \pm 1.07$ & $17.2 \pm 3.0$ & $0.63 \pm 0.02$ & $0.56 \pm 0.24$ & $>0.999$ & $>0.997$ \\
\hline 20 & $0.69 \pm 0.19$ & $0.02 \pm 0.03$ & $0.79 \pm 0.07$ & $0.75 \pm 0.05$ & $0.61 \pm 0.27$ & $12.6 \pm 4.2$ & $0.67 \pm 0.06$ & $0.69 \pm 0.20$ & $>0.999$ & $>0.998$ \\
\hline 40 & $0.61 \pm 0.01$ & $0.01 \pm 0.00$ & $0.79 \pm 0.01$ & $0.75 \pm 0.06$ & $0.38 \pm 0.18$ & $9.4 \pm 1.4$ & $0.67 \pm 0.03$ & $0.49 \pm 0.05$ & $>0.997$ & $>0.992$ \\
\hline 60 & $0.64 \pm 0.05$ & $0.03 \pm 0.00$ & $0.80 \pm 0.04$ & $0.67 \pm 0.04$ & $0.09 \pm 0.08$ & $5.7 \pm 1.2$ & $0.75 \pm 0.07$ & $0.47 \pm 0.12$ & $>0.998$ & $>0.997$ \\
\hline 120 & $0.79 \pm 0.83$ & $0.05 \pm 0.00$ & $0.64 \pm 0.09$ & $0.68 \pm 0.08$ & $0.03 \pm 0.00$ & $2.6 \pm 0.5$ & $0.96 \pm 0.06$ & $0.67 \pm 0.24$ & $>0.998$ & $>0.994$ \\
\hline 180 & $1.46 \pm 0.23$ & $0.09 \pm 0.04$ & $0.66 \pm 0.02$ & $0.68 \pm 0.16$ & $0.03 \pm 0.00$ & $2.9 \pm 1.12$ & $0.87 \pm 0.06$ & $0.98 \pm 1.49$ & $>0.997$ & $>0.993$ \\
\hline 240 & $2.98 \pm 0.45$ & $0.11 \pm 0.00$ & $0.62 \pm 0.09$ & $0.73 \pm 0.05$ & $0.01 \pm 0.00$ & $2.6 \pm 0.3$ & $0.80 \pm 0.07$ & $0.53 \pm 0.03$ & $>0.996$ & $>0.998$ \\
\hline
\end{tabular}

$\lambda 1$ and $\lambda 2$ are the scale parameters established by left (first mode) and right (second mode) Weibull distribution, respectively.

$\mathrm{k} 1$ and $\mathrm{k} 2$ are the shape parameters established by left (first mode) and right (second mode) Weibull distribution, respectively. $\mathrm{R}^{2}$ is the coefficient of determination.

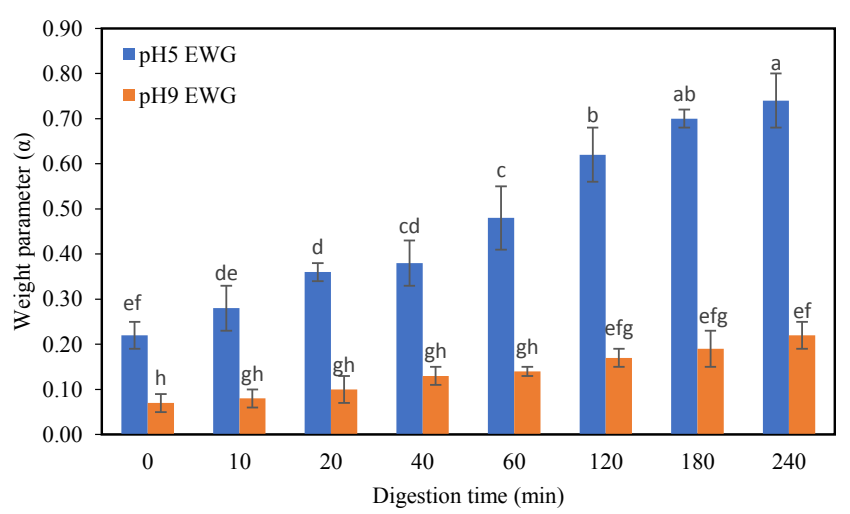

Fig. 6. Temporal evolution of weight parameter $(\alpha)$ of the Mixed Weibull function (proportion of small particles within samples) for $\mathrm{pH} 5$ and $\mathrm{pH} 9 \mathrm{EWGs}$ submitted to $10 \mathrm{~min}$ HGS after 0 to $240 \mathrm{~min}$ prior gastric digestion. Values are given as averages $(n=3)$ with error bars as standard deviations. Different letters indicate significant difference $(\mathrm{p}<0.05)$ as determined using multiple comparison of means (Tukey test).

EWGs. Results showed that in the absence of gastric juice diffusion, the pH 5 EWG ( $\alpha=0.22 \pm 0.03)$ disintegrated into more fine particles than the pH 9 EWG $(\alpha=0.07 \pm 0.02)$. Moreover, the $\alpha$ values of the pH 5 EWG remained significantly higher than that of the pH 9 EWG $(\mathrm{p}<0.05)$ throughout the $240 \mathrm{~min}$ gastric digestion, indicating the pH 5 EWG underwent a higher disintegration rate than pH 9 EWG. These disintegration patterns are in good agreement with the softening kinetics of EWGs during the simulated in vitro gastric phase reported above. Thus, the softening halftime may be a good indicator of the relative rate of breakdown of protein-based hydrogels.

\section{Conclusions}

In this study, the dynamic HGS model was employed to investigate the effect of gastric juice diffusion on softening and disintegration kinetics of two differently structured egg white protein gels ( $\mathrm{pH} 5$ and $\mathrm{pH}$ 9 EWGs). The rate of softening during in vitro gastric digestion was qualitatively related to the disintegration kinetics of $\mathrm{pH} 5$ and $\mathrm{pH} 9$ EWGs. The mixed Weibull function can successfully be used to describe the cumulative distributions of particle surface areas of EWGs during gastric digestion. Particle surface area distributions revealed that $\mathrm{pH} 5$ and $\mathrm{pH} 9$ EWGs follow distinct breakdown patterns when they are exposed to HGS after prior gastric digestion up to $240 \mathrm{~min}$. To summarize, the pH 5 EWG had a faster disintegration which results from both erosion and chipping mechanisms, as well as to some extent fragmentation. In contrast, the $\mathrm{pH} 9 \mathrm{EWG}$ had a much slower disintegration largely governed by erosion. It was assumed these modes of disintegration depend on the internal cohesive forces of the EWG matrices which are closely related to the EWG texture and microstructure. In conclusion, the overall gel softening and disintegration as a result of gastric juice diffusion and mechanical strains was greatly influenced by the characteristics of the EWGs. These findings support the role of EWG structure and biochemical effects on the disintegration patterns of gels during in vitro and in vivo gastric digestion. The derived findings of this study regarding the disintegration kinetics of foods in the stomach should be important for designing novel foods with desired functional properties.

\section{CRediT authorship contribution statement}

Geeshani Somaratne: Conceptualization, Investigation, Resources, Visualization, Writing - original draft. Aiqian Ye: Supervision, Writing review \& editing. Francoise Nau: Supervision, Writing - review \& editing. Maria J. Ferrua: Supervision, Software, Writing - review \& editing. Didier Dupont: Supervision, Writing - review \& editing. R. Paul Singh: Supervision, Writing - review \& editing. Jaspreet Singh: Funding acquisition, Supervision, Project administration, Conceptualization, Writing - review \& editing.

\section{Declaration of Competing Interest}

The authors declare that they have no known competing financial interests or personal relationships that could have appeared to influence the work reported in this paper.

\section{References}

Bornhorst, G. M., Ferrua, M. J., \& Singh, R. P. (2015). A proposed food breakdown classification system to predict food behavior during gastric digestion. Journal of Food Science, 80(5), R924-R934.

Bornhorst, G. M., Kostlan, K., \& Singh, R. P. (2013). Particle size distribution of brown and white rice during gastric digestion measured by image analysis. Journal of Food Science, 78(9), E1383-E1391.

Bornhorst, G. M., \& Paul Singh, R. (2014). Gastric digestion in vivo and in vitro: How the structural aspects of food influence the digestion process. Annual Review of Food Science and Technology, 5, 111-132.

Bornhorst, G. M., \& Singh, R. P. (2012). Bolus formation and disintegration during digestion of food carbohydrates. Comprehensive Reviews in Food Science and Food Safety, 11(2), 101-118.

Brodkorb, A., Egger, L., Alminger, M., Alvito, P., Assunção, R., Ballance, S. Clemente, A. (2019). INFOGEST static in vitro simulation of gastrointestinal food digestion. Nature Protocols, 14(4), 991-1014.

Chen, J. (2009). Food oral processing-A review. Food Hydrocolloids, 23(1), 1-25.

Chen, J. (2015). Food oral processing: Mechanisms and implications of food oral destruction. Trends in Food Science \& Technology, 45(2), 222-228.

Drechsler, K. C., \& Bornhorst, G. M. (2018). Modeling the softening of carbohydratebased foods during simulated gastric digestion. Journal of Food Engineering, 222, $38-48$.

Drechsler, K. C., \& Ferrua, M. J. (2016). Modelling the breakdown mechanics of solid foods during gastric digestion. Food Research International, 88, 181-190.

Ferrua, M. J., Kong, F., \& Singh, R. P. (2011). Computational modeling of gastric digestion and the role of food material properties. Trends in Food Science \& Technology, 22(9), 480-491. 
Ferrua, M. J., \& Singh, R. P. (2015). Human Gastric Simulator (Riddet Model) The Impact of Food Bioactives on Health (pp. 61-71). Cham: Springer.

Guo, Q., Ye, A., Lad, M., Dalgleish, D., \& Singh, H. (2014). Effect of gel structure on the gastric digestion of whey protein emulsion gels. Soft Matter, 10(8), 1214-1223.

Guo, Q., Ye, A., Lad, M., Ferrua, M., Dalgleish, D., \& Singh, H. (2015). Disintegration kinetics of food gels during gastric digestion and its role on gastric emptying: An in vitro analysis. Food \& Function, 6(3), 756-764.

Jalabert-Malbos, M. L., Mishellany-Dutour, A., Woda, A., \& Peyron, M. A. (2007). Particle size distribution in the food bolus after mastication of natural foods. Food Quality and Preference, 18(5), 803-812.

Kamba, M., Seta, Y., Kusai, A., Ikeda, M., \& Nishimura, K. (2000). A unique dosage form to evaluate the mechanical destructive force in the gastrointestinal tract. International Journal of Pharmaceutics, 208(1-2), 61-70.

Kong, F., \& Singh, R. P. (2008a). Disintegration of solid foods in human stomach. Journal of Food Science, 73(5), R67-R80.

Kong, F., \& Singh, R. P. (2008b). A model stomach system to investigate disintegration kinetics of solid foods during gastric digestion. Journal of Food Science, 73(5), E202-E210.

Kong, F., \& Singh, R. P. (2009a). Digestion of raw and roasted almonds in simulated gastric environment. Food Biophysics, 4(4), 365-377.

Kong, F., \& Singh, R. P. (2009b). Modes of disintegration of solid foods in simulated gastric environment. Food Biophysics, 4(3), 180-190.

Kong, F., \& Singh, R. P. (2010). A human gastric simulator (HGS) to study food digestion in human stomach. Journal of Food Science, 75(9), E627-E635.

Krifa, M. A. (2009). Mixed Weibull model for size reduction of particulate and fibrous materials. Powder Technology, 194, 233-238.

Luo, Q., Boom, R. M., \& Janssen, A. E. (2015). Digestion of protein and protein gels in simulated gastric environment. LWT-Food Science and Technology, 63(1), 161-168.

Minekus, M., Alminger, M., Alvito, P., Ballance, S., Bohn, T., Bourlieu, C., ... Brodkorb, A. (2014). A standardised static in vitro digestion method suitable for food-an international consensus. Food \& Function, 5(6), 1113-1124.
Miranda, J., Anton, X., Redondo-Valbuena, C., Roca-Saavedra, P., Rodriguez, J., Lamas, A., ... Cepeda, A. (2015). Egg and egg-derived foods: Effects on human health and use as functional foods. Nutrients, 7(1), 706-729.

Nau, F., Nyemb, K., Lechevalier, V., Floury, J., Serrière, C., Stroebinger, N., ... Dupont, D. (2019). Spatial-temporal changes in pH, structure and rheology of the gastric chyme in pigs as influenced by egg white gel properties. Food Chemistry, 280, 210-220.

Nyemb, K., Causeur, D., Jardin, J., Briard-Bion, V., Guérin-Dubiard, C., Rutherfurd, S. M., ... Nau, F. (2016). Investigating the impact of egg white gel structure on peptide kinetics profile during in vitro digestion. Food Research International, 88, 302-309.

Nyemb, K., Guérin-Dubiard, C., Pézennec, S., Jardin, J., Briard-Bion, V., Cauty, C., .. Nau, F. (2016). The structural properties of egg white gels impact the extent of in vitro protein digestion and the nature of peptides generated. Food Hydrocolloids, 54, 315-327.

Singh, H., Ye, A., \& Ferrua, M. J. (2015). Aspects of food structures in the digestive tract. Current Opinion in Food Science, 3, 85-93.

Somaratne, G., Ferrua, M. J., Ye, A., Nau, F., Floury, J., Dupont, D., \& Singh, J. (2020). Food material properties as determining factors in nutrient release during human gastric digestion: A review. Critical Reviews in Food Science and Nutrition, 1-17.

Somaratne, G., Nau, F., Ferrua, M. J., Singh, J., Ye, A., Dupont, D., ... Floury, J. (2019a). Characterization of egg white gel microstructure and its relationship with pepsin diffusivity. Food Hydrocolloids, 98(2020), Article 105258.

Somaratne, G., Nau, F., Ferrua, M. J., Singh, J., Ye, A., Dupont, D., ... Floury, J. (2019b). In-situ disintegration of egg white gels by pepsin and kinetics of nutrient release followed by time-lapse confocal microscopy. Food Hydrocolloids, 98(2020), Article 105228.

Somaratne, G., Reis, M. M., Ferrua, M. J., Ye, A., Nau, F., Floury, J., ... Singh, J. (2019). Mapping the Spatiotemporal Distribution of Acid and Moisture in Food Structures during Gastric Juice Diffusion Using Hyperspectral Imaging. Journal of Agricultural and Food Chemistry, 67(33), 9399-9410. 